\title{
Quercetin improves myocardial redox status in rats with type 2 diabetes
}

\author{
Nataliia I. Gorbenko ${ }^{1}$, Oleksii Yu. Borikov ${ }^{2}$, Tetiana V. KipryCh ${ }^{1}$, Olha V. Ivanova ${ }^{1}$, \\ Kateryna V. TARAN ${ }^{1}$, Tetiana S. Litvinova ${ }^{1}$ \\ ${ }^{1}$ V. Danilevsky Institute for Endocrine Pathology Problems, National Academy of Medical Sciences of Ukraine, \\ Kharkiv, Ukraine; ${ }^{2}$ V. N. Karazin Kharkiv National University, Kharkiv, Ukraine \\ E-mail: gorbenkonat58@ukr.net
}

Objective. Emerging data indicate that oxidative stress is closely associated with the pathogenesis of cardiovascular disease in type 2 diabetes mellitus (T2DM). The present study aimed to assess the effect of the most abundant flavonoid in the human diet quercetin (Q) on the myocardial redox status in rats with T2DM.

Methods. T2DM was induced in male Wistar rats by a high caloric diet (for 14 weeks) and two streptozotocin $(25 \mathrm{mg} / \mathrm{kg}$ b.w.) injections applied in four weeks of the diet, once a week for two weeks. The Q was administered intragastrically by gavage in a dose of 10 or $50 \mathrm{mg} / \mathrm{kg}$ of the body weight for 8 weeks starting from the 8th day after the last streptozotocin injection. The control rats received citrate buffer and seven days after the last STZ injection, basal glucose levels were measured in all animals.

Results. Administration of $\mathrm{Q}$ increased insulin sensitivity in diabetic rats with more pronounced effect at a dose of $50 \mathrm{mg} / \mathrm{kg}$ b.w. The Q also decreased free radical oxidation in the heart mitochondria of diabetic animals, thus limiting the formation of advanced oxidation protein products in a dose-dependent manner and normalized the activity of antioxidant enzymes (superoxide dismutase, glutathione peroxidase, glutathione reductase) in cardiac mitochondria independently of the dose used. In addition, the $\mathrm{Q}$ in both doses prevented the development of oxidative stress in the T2DM rats cardiomyocytes by reducing NADPH oxidase and xanthine oxidase activities.

Conclusions. The findings demonstrate that $\mathrm{Q}$ in both doses $10 \mathrm{mg} / \mathrm{kg}$ and $50 \mathrm{mg} / \mathrm{kg}$ can protect from the development of oxidative stress in cardiomyocytes in the diabetic rats. The present data indicate that the use of Q may contribute to the amelioration of cardiovascular risk in patients with T2DM.

Key words: quercetin, type 2 diabetes mellitus, cardiomyocytes, oxidative stress

Diabetes mellitus (DM) is one of the fastest growing global health emergencies of the $21^{\text {st }}$ century. According to the International Diabetes Federation, 463 million people worldwide had diabetes in 2019, and this number is assumed to reach 700 million by the year 2045. DM is associated with a wide range of cardiovascular conditions that collectively increase the risk of the cardiovascular death by $132 \%$ in diabetics compared to individuals without DM (IDF Diabetes Atlas 2019).
The DM is known to cause specific changes in the myocardium structure and function independent of coronary artery disease or hypertension that is commonly defined as diabetic cardiomyopathy (DCM). DCM is manifested by diastolic dysfunction followed by abnormalities in systolic function, which can lead to a heart failure (Liu et al. 2014). It is also known that metabolic disturbances in cardiomyocytes at DCM (hypertrophy, inflammation, apoptosis, fibrosis) are closely associated with the develop-

Corresponding author: Nataliia I. Gorbenko, Prof., Department of Experimental Pharmacology and Toxicology, V. Danilevsky Institute for Endocrine Pathology Problems, National Academy of Medical Sciences of Ukraine, Alchevskykh str. 10, Kharkiv 61002, 
ment of oxidative stress (Kayama et al. 2015).

Reactive oxygen species (ROS), including superoxide anion, hydroxyl radical, and hydrogen peroxide are critical signaling molecules with important roles in both cardiac physiology and disease. Both cytosolic sources, including NADPH oxidases (NOX), xanthine oxidase (XO), cyclooxygenases, and cytochrome P450 enzymes, and mitochondrial sources, such as the respiratory chain and monoamine oxidases, contribute to the intracellular ROS pool. Under physiological conditions cardiac ROS signaling regulates the heart development and cardiomyocyte maturation, cardiac calcium handling, excitation contraction coupling, and vascular tone. However, pathological conditions of unregulated ROS production leading to the elevated ROS levels, which can result in oxidative stress through oxidative damage of DNA, proteins, and lipids, as well as mitochondrial dysfunction and cell death (Peoples et al. 2019). Indeed, dysregulated ROS production and oxidative stress have been implicated in a lot of cardiac diseases, including diabetic cardiomyopathy (Ritchie and Abel 2020).

The excessive ROS production by mitochondria can directly affect the contractile function of the myocardium by oxidative modification of enzymes and ion channels that participate in the regulation of the excitation-relaxation cycle (Brown and Griendling 2015; Bai et al. 2016). In addition, ROS stimulate proliferation of cardiomyocytes and activate fibroblasts and matrix metalloproteinases, which lead to hypertrophy and remodeling of the myocardium resulting in the formation of the heart failure (D'Oria et al. 2020). Therefore, it is suggested that pharmacological action aimed at reducing ROS overproduction may be effective for the prevention and correction of diabetic cardiovascular complications.

At present, it has been established that dietary intake of natural polyphenols, particularly flavonoids, can reduce the risk of diabetes and cardiovascular diseases and the protective mechanisms may not only be dependent on the antioxidant and antiinflammatory effects of flavonoids, but also include their properties affecting glycemia, glucose utilization, and insulin secretion (Ghorbani et al. 2019; Lutz et al. 2019).

Quercetin (Q; 3,5,7,3'4'-pentahydroxy flavon) is the most abundant flavonoid in the human diet. There is a wide range of biological functions of $\mathrm{Q}$ including effects on pathways involved in inflammation, diabetes, and cardiovascular diseases (Zahedi et al. 2013). Several studies have demonstrated the mechanisms of the antidiabetic effects of the Q, including decreased lipid peroxidation, increased activity of antioxidant enzymes (e.g., superoxide dismutase, SOD; glutathione peroxidase, GPX; catalase, CAT), reduced absorption of glucose in the intestine due to inactivation of the transporter GLUT2 and others (Shi et al. 2019; Salehi et al. 2020). The cardioprotective effect of $\mathrm{Q}$ on differentiated cardiomyocytes, due to inactivation of mitogen-activated protein kinase and protein kinase B signaling pathways, has also been shown (Daubney et al. 2015).

Future research devoted to understanding the Q cardioprotective action mechanisms in diabetes could contribute to the diabetes care improvement.

The aim of the present work was to study the effect of the quercetin on the redox status of cardiomyocytes in rats with type 2 diabetes mellitus (T2DM).

\section{Materials and methods}

Chemicals. All chemicals used were of analytical reagent grade quality and purchased from Sigma Chemical Co. (St. Louis, MO, USA). Quercetin was provided by the PJSC SIC Borshchahivskiy ChemicalPharmaceutical Plant (Kyiv, Ukraine), and contained minimum $96.5 \%$ of active substance.

Experimental design. The present study was approved by the bioethics committee of the "V. Danilevsky Institute for Endocrine Pathology Problems of National Academy of Medical Sciences of Ukraine" (Kharkiv, Ukraine) and performed in accordance with the European Convention for the Protection of Vertebrate Animals Used for Experimental and Other Scientific Purposes (Strasbourg, 1986).

The experiments were performed on 32 male Wistar rats (12-week-old, 200-230 g body weight, b.w.), which were housed in Plexiglas cages (3 animals per cage) at a temperature of $22 \pm 1^{\circ} \mathrm{C}$ in a constant 12-hour light/dark cycle.

The animal model of T2DM induced by a high caloric diet combined with multiple low dose streptozotocin (STZ) injections was used. The model provides the development of two main features of T2DM: the high caloric diet initiates insulin resistance and the low-dose STZ induces a mild impairment of insulin secretion. Thus, the model mimics the natural history of the disease events (from insulin resistance to $\beta$-cell dysfunction) as well as the metabolic characteristics of human T2DM (Skovso 2014).

Control intact rats $(n=8)$ were fed a standard diet for 14 weeks. Experimental rats $(n=24)$ were fed the high calorie diet containing 15\% lard, 25\% sucrose, $1 \%$ bile salts and $59 \%$ standard feed for 14 weeks. The animals had free access to water. In four weeks, 
experimental rats were intraperitoneally (i.p.) injected with STZ $(25 \mathrm{mg} / \mathrm{kg}$ b.w.) once per week for two weeks (Lin et al. 2010). Control rats received citrate buffer following the same scheme. Seven days after the last STZ injection, basal glucose was measured in all animals, and experimental rats were divided into three groups: untreated diabetic rats (Diabetes, $\mathrm{n}=8$ ) and diabetic rats treated with $\mathrm{Q}$ in a dose of 10 $\mathrm{mg} / \mathrm{kg}$ b.w. (Diabetes+Q10, $\mathrm{n}=8$ ) or $50 \mathrm{mg} / \mathrm{kg}$ b.w. (Diabetes+Q50, $\mathrm{n}=8$ ) once per day intragastrically by gavage for 8 weeks after diabetes induction. Untreated diabetic rats received vehicle along the same scheme.

The animals were sacrificed according to the protocol of the ethics committee.

Measurement of glucose homeostasis. The intraperitoneal insulin tolerance test (IPITT) was performed in overnight fasted rats. Blood glucose concentrations were initially measured at the basal condition ( $0 \mathrm{~min})$, then the animals were given an i.p. injection of insulin $0.25 \mathrm{U} / \mathrm{kg}$ b.w. (Actrapid, Novo Nordisk, Agsvaerd, Denmark) followed by an i.p. injection of glucose $(2 \mathrm{~g} / \mathrm{kg}$ ) (Bowe et al. 2014). Subsequently, tail blood glucose levels were measured using a glucose analyzer Eksan-G (Analita Firm Joint Stock Company Ltd., Vilnius, Republic of Lithuania) at 15, 30, 60, 90 and 120 min after the glucose load.

Isolation of mitochondria. Mitochondria were isolated by conventional procedures. Freshly excised rat heart was homogenized in a medium containing $0.18 \mathrm{M} \mathrm{KCl}, 10 \mathrm{mM}$ EDTA, $0.5 \%$ bovine serum albumin (BSA), 10 mM HEPES, pH 7.4. Homogenates were cleared from debris and nuclei by two times centrifugation at $500 \mathrm{~g}\left(10 \mathrm{~min}\right.$ at $\left.4^{\circ} \mathrm{C}\right)$. Mitochondria were pelleted from the supernatants at $10000 \mathrm{~g}$ $\left(15 \mathrm{~min}\right.$ at $4^{\circ} \mathrm{C}$ ) and resuspended in isolation buffer.

The postmitochondrial supernatant fractions were used for determination of XO and NOX activities. To remove EDTA and albumin, mitochondrial pellets were centrifuged at $10000 \mathrm{~g}\left(15 \mathrm{~min}, 4^{\circ} \mathrm{C}\right)$ and resuspended in wash buffer containing $0.18 \mathrm{M} \mathrm{KCl}$ and 10 mM HEPES (pH 7.4) twice (Di Lisa et al. 1994).

Spectrophotometry. All spectrophotometry was performed using double-beam UV-VIS spectrophotometer Shimadzu UV-1800 (Shimadzu Corporation, Kyoto, Japan).

Measurement of advanced oxidation protein products (AOPP). Determination of AOPP levels was performed by the modified method of WitkoSarsat and colleagues (Sagor et al. 2015). The heart mitochondria ( $0.2 \mathrm{mg}$ protein) were treated with $0.1 \%$ Triton-X100 and diluted in PBS (pH 7.4) solution. KI $(1.16 \mathrm{M})$ was added to assay medium, followed $2 \mathrm{~min}$ later by addition of glacial acetic acid. The absor- bance of the reaction mixture was immediately read at $340 \mathrm{~nm}$ against the blank. AOPP concentrations were expressed as nmol-equivalent chloramine $\mathrm{T} / \mathrm{mg}$ protein.

Measurement of enzyme activity. NOX activity was examined as $\mathrm{NADPH}$-dependent $\mathrm{O}_{2}^{-}$production by postmitochondrial supernatant fraction using SOD-inhibitable ferricytochrome c reduction (Li et al. 2002). The postmitochondrial fraction of the heart homogenate (1 $\mathrm{mg}$ protein) supplemented with $10 \mathrm{mM}$ Tris- $\mathrm{HCl}$ ( $\mathrm{pH} 7.8), 500 \mu \mathrm{M}$ cytochrome c, $100 \mu \mathrm{M} \mathrm{NADPH}$, was incubated at $37^{\circ} \mathrm{C}$ for $30 \mathrm{~min}$ with or without $200 \mathrm{U} / \mathrm{ml} \mathrm{SOD}$. Cytochrome c reduction was measured by reading absorbance at $550 \mathrm{~nm}$ $\left(\varepsilon=21 \mathrm{mM}^{-1} \mathrm{~cm}^{-1}\right)$.

$\mathrm{XO}$ activity was assayed in air-equilibrated PBS ( $\mathrm{pH}$ 7.4) solution that contained postmitochondrial fraction of the heart homogenate $(1 \mathrm{mg}$ protein) at $37^{\circ} \mathrm{C}$ after addition of xanthine (final concentration $360 \mu \mathrm{M}$ ) by measurement of uric acid production from the change in absorbance at $295 \mathrm{~nm}$ $\left(\varepsilon=9500 \mathrm{M}^{-1} \mathrm{~cm}^{-1}\right)$ (Lee et al. 2014).

Mn-SOD activity in the mitochondrial suspension was detected by inhibition of nitroblue tetrazolium (NBT) reduction caused by xanthine-XO system as $\mathrm{O}_{2}{ }^{-}$generator and the absorbance was finally determined at $560 \mathrm{~nm}$. The reaction mixture contained heart mitochondria $(0.02 \mathrm{mg}$ protein), $0.05 \mathrm{M}$ carbonate buffer (pH 10.2), $0.1 \mathrm{mM}$ EDTA, $0.1 \mathrm{mM}$ xanthine, $25 \mu \mathrm{M}$ NBT, $1 \mathrm{mU} / \mathrm{ml} \mathrm{XO}$. The results were expressed in arbitrary units (a.u.) of SOD activity per mg protein. One a.u. means the enzyme amount causing 50\% inhibition of NBT reduction rate (Wang et al. 2018).

Glutathione reductase (GR) activity was measured by tracking the oxidation of NADPH at $340 \mathrm{~nm}$ in the reaction of oxidized glutathione (GSSG) reduction. To perform the reaction, mitochondria from the heart $(0.1 \mathrm{mg}$ protein) were incubated for $10 \mathrm{~min}$ at $37^{\circ} \mathrm{C}$ in assay buffer containing $20 \mathrm{mM}$ Tris- $\mathrm{HCl}$ (pH 7.4), 0.25 mM EDTA, $10 \mu \mathrm{M}$ FAD, 3 mM GSSG and $0.1 \mathrm{mM}$ NADPH (Raza and John 2004).

The estimation of GPX activity was made based on the enzyme ability to catalyze tert-butyl hydroperoxide degradation using reduced glutathione (GSH) as a substrate. Reaction mixture ( $\mathrm{pH} 7.0)$ contained heart mitochondria (0.1 $\mathrm{mg}$ protein), $0.56 \mathrm{mM}$ $\mathrm{NADPH}, 1.0 \mathrm{U} / \mathrm{ml} \mathrm{GR}, 7.5 \mathrm{mM}$ sodium azide, $5 \mathrm{mM}$ GSH, $5 \mathrm{mM}$ EDTA and $0.05 \mathrm{M}$ phosphate buffer. Tert-butyl hydroperoxide $(23 \mathrm{mM})$ was added to initiate the reaction. The rate of GSSG formation was determined by GR reaction from decrease in the absorbance of probes at $340 \mathrm{~nm}$ (Antunes et al. 2002). 
Measurement of protein content in the samples. Mitochondrial protein was determined by the Lowry method modified by Miller, with BSA as the standard (Lowry et al. 1951; Miller 1959).

Statistical analysis. Data are presented as mean \pm standard error of mean (SEM). The Shapiro-Wilk test was used to test normality of data distribution. For multiple comparisons of data with a normal distribution, a parametric one-way analysis of variance (ANOVA) was performed and the Student-NewmanKeuls method was used to test differences in means. Values were considered statistically significant at $\mathrm{p}<0.05$.

\section{Results}

We revealed that the level of basal glucose in rats fed with high caloric diet and injected with STZ was significantly higher than in control group (Table 1).
In addition, the areas under the glycemic curves (AUC) obtained during IPITT were almost three times larger in diabetic animals compared to control ones (Table 1, Figure 1). These data confirm the development of relative insulin deficiency and insulin resistance in experimental rats.

Administration of $\mathrm{Q}$ had no significant impact on the basal hyperglycemia of diabetic animals. However, $Q$ affected insulin sensitivity in rats with T2DM in a dose-dependent manner, decreasing IPITT AUC by $27 \%$ in experimental group receiving $10 \mathrm{mg} / \mathrm{kg}$ of the drug, and by $41 \%$ in the group receiving $50 \mathrm{mg} / \mathrm{kg}$ of Q compared to animals receiving vehicle (Table 1, Figure 1).

AOPP level in the heart mitochondria of experimental rats was increased by $66 \%$ confirming the development of oxidative stress in T2DM (Figure 2). $\mathrm{Q}$ administration resulted in lowering of AOPP accumulation in the heart of diabetic animals depending

Table 1

Indexes of glucose homeostasis in control and diabetic rats

\begin{tabular}{lcccc}
\hline Group & Basal glucose $(\mathrm{mmol} / \mathrm{l})$ & $\mathrm{p}$-value & IPITT (AUC) $(\mathrm{mmol} / \mathrm{l}) \times$ min & $\mathrm{p}$-value \\
\hline Control & $3.75 \pm 0.08$ & & $568.20 \pm 37.54$ & \\
Diabetes & $9.02 \pm 1.19$ & $\mathrm{p}<0.001^{*}$ & $1691.06 \pm 147.74$ & $\mathrm{p}<0.001^{*}$ \\
Diabetes+Q10 & $8.50 \pm 1.12$ & $\mathrm{p}<0.001^{*}$ & $1235.21 \pm 164.86$ & $\mathrm{p}<0.01^{*} \mathrm{p}<0.05 \#$ \\
& & $\mathrm{NS \#}$ & $\mathrm{p}<0.01^{*} \mathrm{p}<0.01 \#$ \\
Diabetes+Q50 & $8.32 \pm 0.61$ & $\mathrm{p}<0.001^{*}$ & $999.32 \pm 152.56$ & $\mathrm{p}<0.05 \dagger$ \\
& & $\mathrm{NS \#}$ & $\mathrm{NS} \dagger$ & \\
\hline
\end{tabular}

Data are shown as mean \pm SEM $(n=8) ;{ }^{*}$ - statistical difference vs. Control; \# - statistical difference vs. Diabetes; $\dagger$ - statistical difference vs. Diabetes+Q10; NS - not significant.

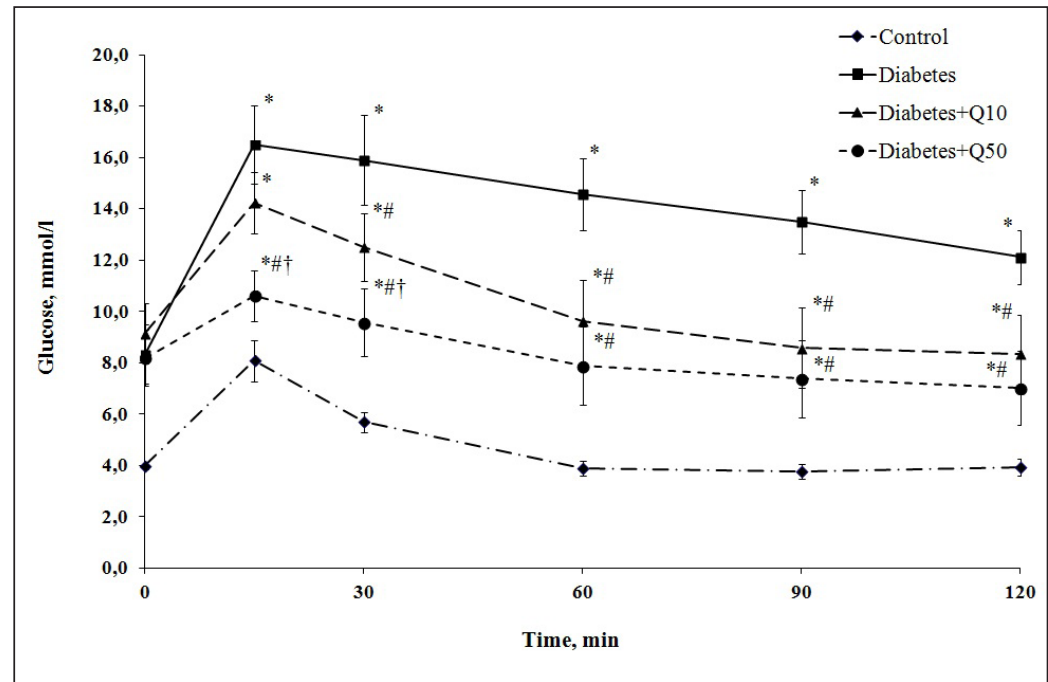

Figure 1. Dynamics of glycemia during the intraperitoneal insulin tolerance test (IPITT) in control and diabetic rats. Data are shown as mean $\pm \operatorname{SEM}(\mathrm{n}=8) ;{ }^{*} \mathrm{p} \leq 0.05$ - statistical difference vs. Control; \# $\mathrm{p} \leq 0.05$ - statistical difference vs. Diabetes; $\dagger \mathrm{p} \leq 0.05$ - statistical difference vs. Diabetes+Q10. 


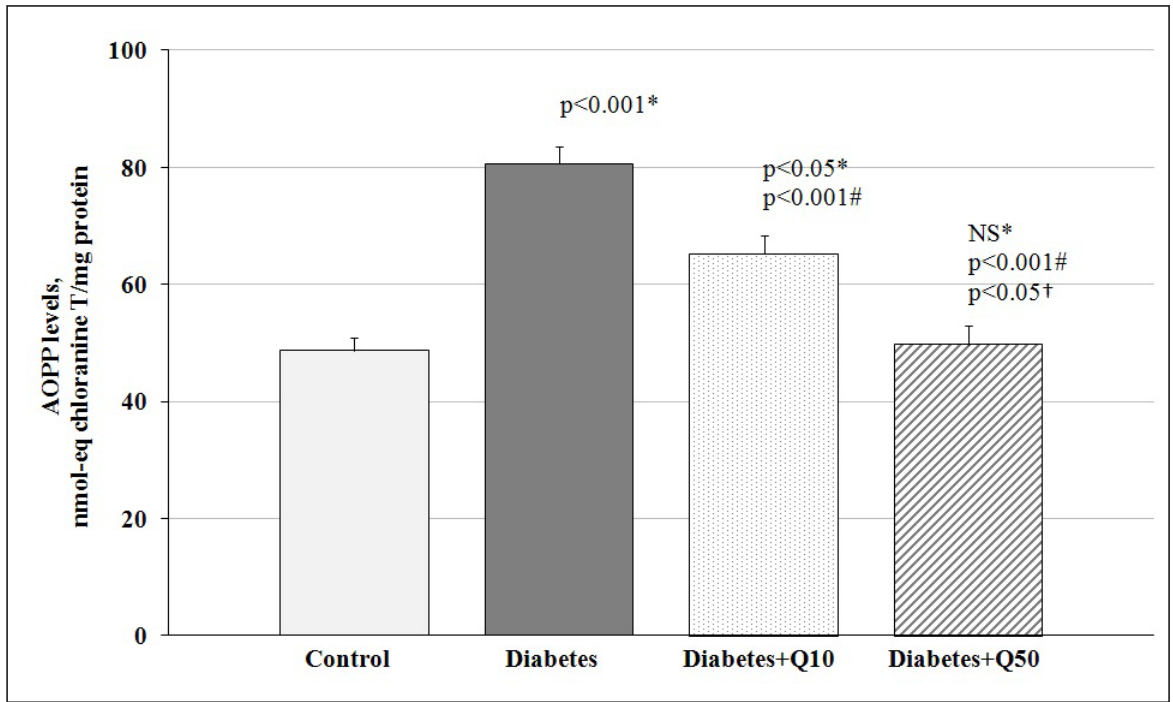

Figure 2. The advanced oxidation protein products (AOPP) levels in the isolated heart mitochondria of rats. Data are shown as mean $\pm \operatorname{SEM}(n=8)$; ${ }^{*}$ statistical difference vs. Control; \#statistical difference vs. Diabetes; †statistical difference vs. Diabetes+Q10; NS - not significant.

on the dose of the drug. In the experimental group receiving $50 \mathrm{mg} / \mathrm{kg}$ of Q, the concentration of AOPP decreased to the level of the control group, suggesting antioxidant properties of $\mathrm{Q}$ (Figure 2).

As can be seen in Figure 3, oxidative stress in the heart mitochondria of rats with T2DM was accompanied by induced activity of antioxidant enzymes - Mn-SOD, GPO and GR. The Q administration in both doses normalized the activities of studied antioxidant enzymes in diabetic animals to the level of the control group (Figure 3).

It was found that T2DM was associated with $65 \%$ and $52 \%$ increase of NOX and XO activities, two primary cytosolic sources of $\mathrm{O}_{2}^{-}$in cardiomyocytes, respectively, in the postmitochondrial fraction of the heart homogenate of experimental rats (Figure 4). The use of Q led to normalization of NOX and XO activities in the heart of diabetic animals independently of dose (Figure 4).

\section{Discussion}

At present, the oxidative stress defined as a sustained increase in free radicals due to an imbalance in their production and utilization, is thought to be a universal mechanism that combines the various pathogenetic pathways of diabetic cardiovascular complications (Huynh et al. 2014).

Oxidative stress induced by hyperglycemia plays a leading role in the pathogenesis of T2DM (Shah and Brownlee 2016). The main pathological features of
T2DM are reduced insulin secretion and decreased sensitivity to the hormone in peripheral tissues. At the first stage of our study, insulin resistance was modeled in rats using a high calorie diet. During four weeks, rats receiving a high calorie diet were i.p. injected with STZ to reproduce a relative insulin deficiency. Elevated levels of basal glycemia and increased AUC in IPITT indicated the development of insulin deficiency and insulin resistance in model animals.

Administration of Q didn't affect the levels of basal hyperglycemia of diabetic rats, but improved insulin sensitivity in a dose-dependent manner. The results are consistent with data from other studies on the ability of Q to reduce insulin resistance (Shi et al. 2019). The $Q$ increases glucose utilization in peripheral tissues and reduces hepatic glucose production. The flavonoid is reported to activate an insulinindependent mechanism involving AMP-dependent protein kinase, which stimulates the glucose transporter GLUT4 translocation into the plasma membrane in skeletal muscle and downregulates the key gluconeogenesis enzymes in liver (phosphoenolpyruvate carboxykinase and glucose 6-phosphatase) (Eid and Haddad 2017). The improvement of insulin sensitivity by $\mathrm{Q}$ may also be due to its ability to increase adiponectin expression in the white adipose tissue independently of the expression of peroxisome proliferator-activated receptors $\alpha$ (Wein et al. 2010).

The antidiabetic effect of $\mathrm{Q}$ can also be realized by reducing the absorption of glucose in the intestine through inactivation of the glucose transporter 


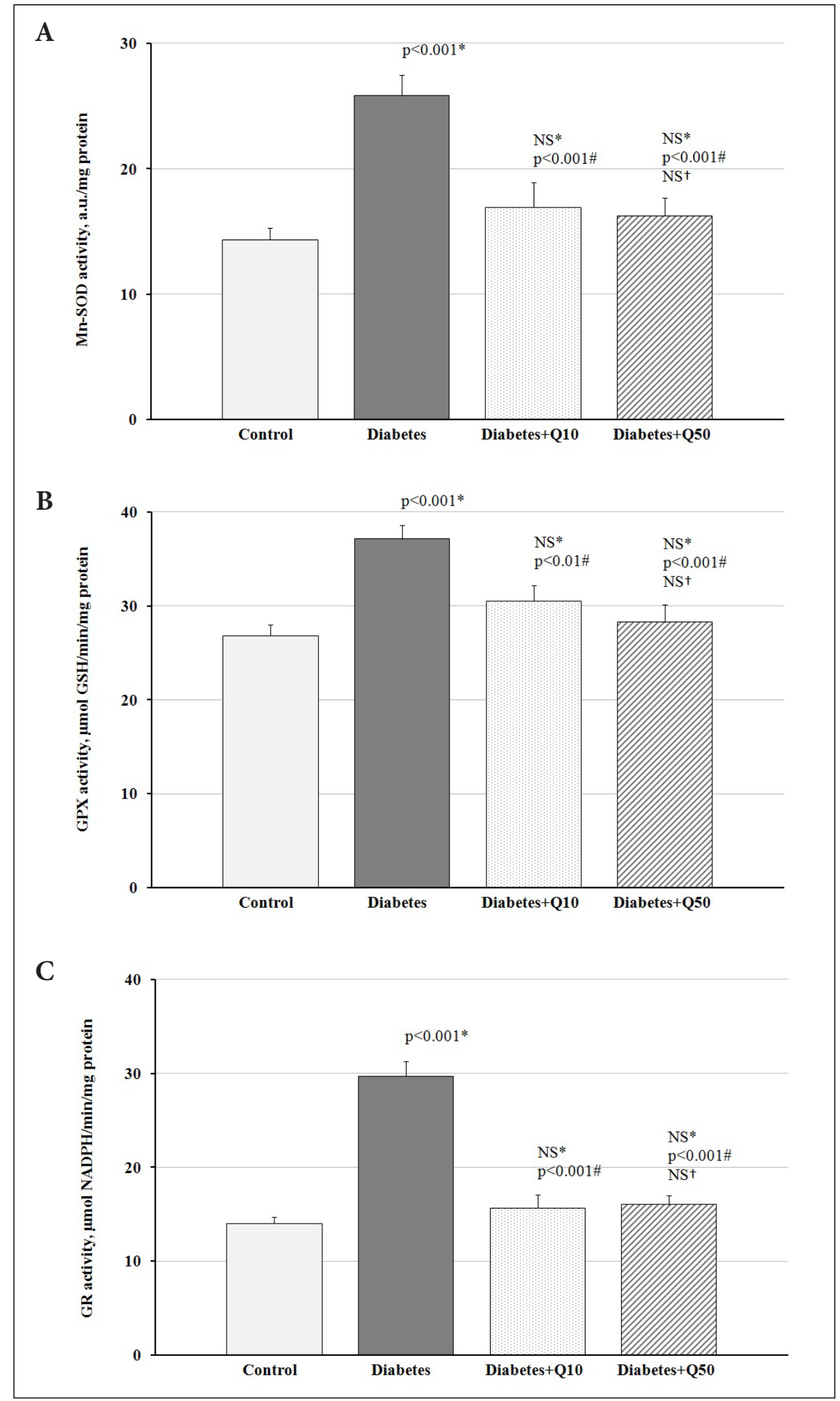

Figure 3. Mn-superoxide dismutase (SOD) activity (A), glutathione peroxidase (GPX) activity (B) and glutathione reductase (GR) activity (C) in the isolated heart mitochondria of rats. Data are shown as mean \pm SEM $(n=8)$; ${ }^{*}$ statistical difference vs. Control; \#statistical difference vs. Diabetes; $\dagger$ statistical difference vs. Diabetes+Q10; NS - not significant. 
GLUT2 (Gauer et al. 2018) and inhibition of the intestinal a-glucosidases activity (Pereira et al. 2011). In addition, the $\mathrm{Q}$ has been shown to inhibit the enzyme $11 \beta$-hydroxysteroid dehydrogenase-1, which plays a key role in the development of obesity and T2DM by affecting the action of glucocorticoid hormones in the liver, adipose tissue and pancreatic $\beta$-cells (Torres-Piedra et al. 2010).

It is assumed that both the development and progression of diabetic complications are due to an increase in the production of ROS (Kayama et al. 2015). In cardiomyocytes, ROS are generated by mitochondrial electron transport chain (ETC), NOX and
XO (Tsutsui et al. 2011). It can be argued that mitochondria are the main oxidative stress contributors in T2DM (Shah and Brownlee 2016). The development of oxidative stress in mitochondria is accompanied by disruption of redox-sensitive signaling pathways, decreased oxidative phosphorylation and ATP production, damage of mitochondrial DNA and, by consequence, a further increase in ROS production. As a result, the pathogenic cascade of molecular events, which amplifies itself, leads to the launch of proapoptotic signaling pathways and cell death. Given the importance of mitochondria in cell metabolism, their dysfunction may lead to various diseases

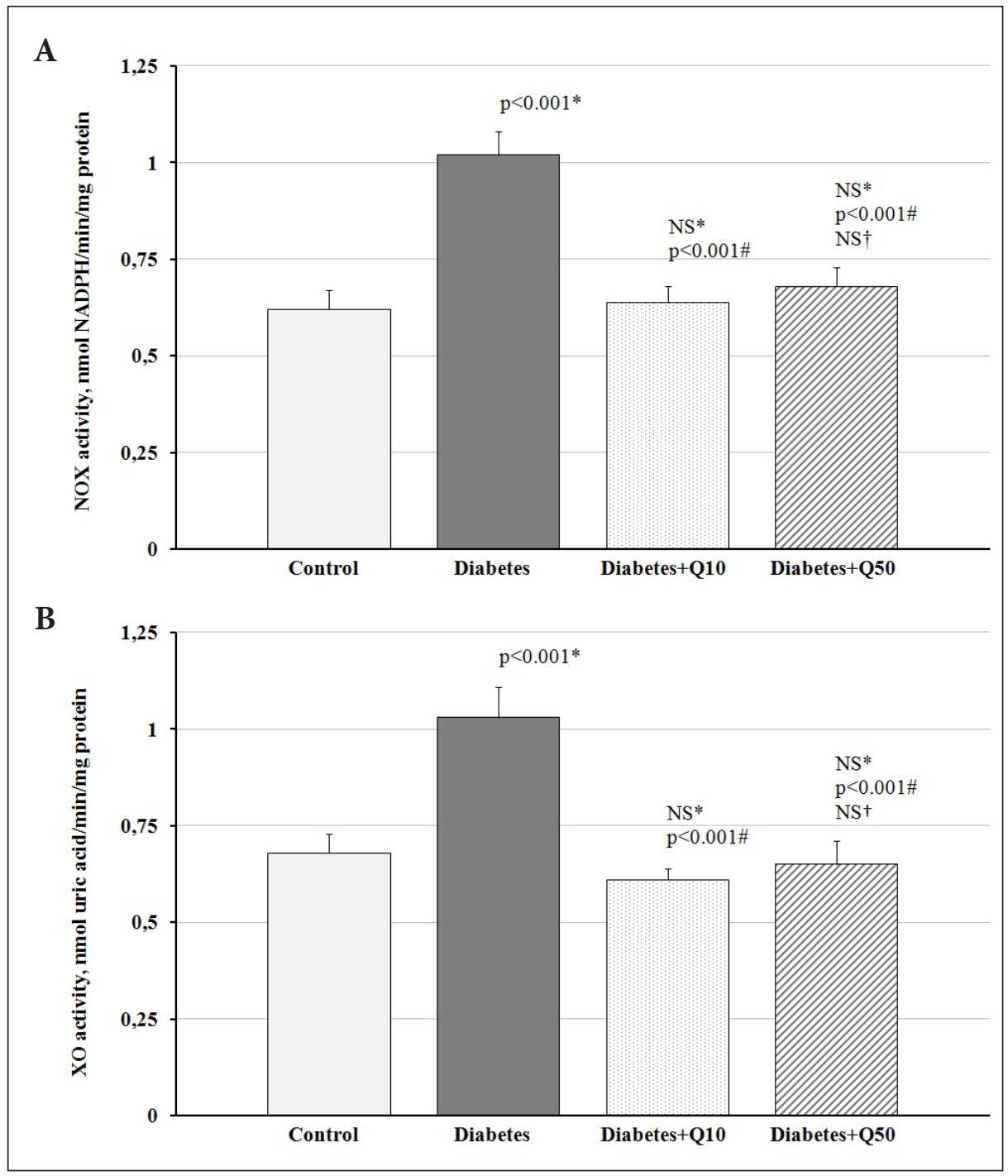

Figure 4. NADPH oxidases (NOX) activity (A) and xanthine oxidase (XO) activity (B) in the postmitochondrial fraction of the heart homogenate of rats. Data are shown as mean \pm SEM $(\mathrm{n}=8)$; ${ }^{*}$ statistical difference vs. Control; \#statistical difference vs. Diabetes; $\dagger$ statistical difference vs. Diabetes+Q10; NS - not significant. 
including cardiovascular pathology. Mitochondrial dysfunction occurs in patients with coronary heart disease, cardiomyopathy, heart failure, stroke, and T2DM (Bai et al. 2016).

In our study, the development of oxidative stress in the heart mitochondria of diabetic rats was evidenced by accumulation of AOPP. The concentration of AOPP is a relatively novel marker of oxidative stress, which reflects the overall redox status of proteins in cells and tissues. AOPP are reported to be elevated in patients with DM, cardiovascular diseases, hypertension, atherosclerosis (Conti et al. 2019), and the level correlates with insulin resistance and the presence of severe diabetic complications (Gradinaru et al. 2013; Taylor et al. 2015). Oxidative protein modifications play a key role in the development of diabetic myocardial dysfunction. Redox changes of protein structures may result in dissociation of catalytic subunits of enzymes, unfolding, aggregation or fragmentation of proteins involved in contractility, excitation contraction coupling, protein folding, antioxidant defense, metabolism and $\mathrm{Ca}^{2+}$ handling in the diabetic heart (Varga et al. 2015). It has also been found that AOPP induce proapoptotic signaling in cardiomyocytes leading to the development of DCM (Zhang et al. 2016).

In animals treated with $\mathrm{Q}$ in a dose of $10 \mathrm{mg} / \mathrm{kg}$, a significant reduction of AOPP in the heart mitochondria was observed, whereas a dose of $50 \mathrm{mg} / \mathrm{kg}$ of Q completely normalized this marker as compared to rats that received vehicle.

The antioxidant effect of the $\mathrm{Q}$ in mitochondria may include several main mechanisms. Flavonoids have an ability to scavenge ROS due to the hydroxyl configuration of B-ring in the structure (Kumar and Pandey 2013). The direct scavenging of $\mathrm{O}_{2}^{-}$generated in mitochondrial complex III of the ETC in isolated rat heart mitochondria has been shown for Q (Dudylina et al. 2019). Besides, flavonoids can attenuate the formation of ROS in mitochondria through the inhibition of complex I and III of the ETC. Q inhibition of complex I activity significantly decreased $\mathrm{H}_{2} \mathrm{O}_{2}$ production in isolated rat heart mitochondria (Lagoa et al. 2011). In addition, the reduction in mitochondrial ROS generation by flavonoids was found to be associated with partial uncoupling properties, particularly, in cardiac mitochondria (Bernatoniene et al. 2014). Furthermore, flavonoids have been shown to stimulate mitochondrial biogenesis through the induction of transcriptional co-activator PGC-1 $\alpha$ and its upstream regulator SIRT1. The latter leads to stimulation of a series of transcription factors (NRF1, NRF2 and estrogen-related- $\alpha$ ), involved in regulation of energy metabolism and preservation of homeostasis in mitochondria (Kicinska and Jarmuszkiewicz 2020).

As a result of our experiment, the increase of oxidative stress in the heart mitochondria of diabetic rats was accompanied by induction of the activity of antioxidant enzymes - Mn-SOD, GPO and GR. It is well established, that a major mechanism in the cellular defense against oxidative stress is activation of the Keap1/Nrf-2-dependent signaling pathway, which controls the expression of genes whose protein products are involved in the detoxication and elimination of reactive oxidants (Nguyen et al. 2009). In this regard, the observed induction of antioxidant enzymes in the heart of experimental animals is the implementation of a negative feedback aimed to maintain the redox homeostasis.

Administration of $\mathrm{Q}$ in a both doses led to decrease the activity of Mn-SOD, GPO and GR in the cardiac mitochondria of experimental animals to values statistically indifferent from the control group. Though, Q is known to induce the activity of the above enzymes (Shi et al. 2019), our results indicate that the antioxidant effect of $\mathrm{Q}$ in cardiomyocytes in T2DM is realized more by its ability to prevent hyperproduction of ROS, and by consequence the development of mitochondrial dysfunction, than by stimulation of antioxidant defense system. Previously, it was shown that $\mathrm{Q}$ use increases mitochondria oxidative capacity and the activity of some enzymes of the Krebs cycle in the heart of rats with T2DM (Gorbenko et al. 2019).

As noted above, mitochondria are the primary, but not the only source of ROS in cardiomyocytes. The second important factor in the development of oxidative stress in diabetic heart is NOX, with NOX2 and NOX4 as the major myocardial isoforms. The main function of NOX is to generate ROS. NOX2 is localized in the plasma membrane and participates in intracellular redox signaling of the angiotensin II receptor and others, while NOX4 particularly has a mitochondrial localization signal and exhibits constitutive activity (Cave et al. 2005). It has been demonstrated that incubation of rat cardiomyocytes with early-glycated proteins stimulated ROS production through a protein kinase C (PKC)-dependent activation of NOX2 (Zhang et al. 2006). Furthermore, cardiac hypertrophy, fibrosis, and apoptosis were found to be associated with upregulated NOX2 in the heart of mice with type 1 and type $2 \mathrm{DM}$ (Ritchie et al. 2007; Huynh et al. 2013). An additional source of ROS in cardiomyocytes is $\mathrm{XO}$, which catalyzes oxidation of hypoxanthine and xanthine to uric acid using $\mathrm{O}_{2}$ as an electron receptor and producing 
$\mathrm{O}_{2}{ }^{-}$and $\mathrm{H}_{2} \mathrm{O}_{2}$ in the process. Although the contribution of $\mathrm{XO}$ reaction to the development of oxidative stress in diabetes has not been studied enough, XO inhibitors were shown to ameliorate cardiovascular dysfunction in the model of pacing-induced heart failure (Amado et al. 2005). In our study, T2DM led to a significant increase in NOX and XO activities in the heart of experimental rats. At the same time, Q administration independently from the dose normalized the activity of enzymes. To date, several studies have shown the ability of Q to inhibit NOX activity by both reducing expression of its subunits and preventing its activation through extracellular stimuli. The second mechanism could be realized by reducing the phosphorylation of the regulatory subunit p47phox due to the inhibitory effect of flavo- noid on PKC (Redondo et al. 2012; Jimenez et al. 2015). Besides, $Q$ and its metabolites are known to inhibit the activity of $\mathrm{XO}$ in a selective way, forming the conjugated three-ring structure with the active site and specific hydrogen-bonding interactions with catalytically relevant residues of the enzyme (Takahama et al. 2011; Cao et al. 2014).

In summary, our study showed that $\mathrm{Q}$ in a dosedependent manner decreased free radical oxidation in the myocardial mitochondria of rats with T2DM, thus limiting AOPP formation. In addition, the $\mathrm{Q}$ in a dose of both $10 \mathrm{mg} / \mathrm{kg}$ and $50 \mathrm{mg} / \mathrm{kg}$ prevented the development of oxidative stress in the heart of diabetic rats reducing NOX and XO activities. The obtained data suggest that the use of $Q$ may contribute to the amelioration of cardiovascular risk in T2DM.

\section{References}

Amado LC, Saliaris AP, Raju SVY, Lehrke S, St John M, Xie J, Stewart G, Fitton T, Minhas KM, Brawn J, Hare JM. Xanthine oxidase inhibition ameliorates cardiovascular dysfunction in dogs with pacing-induced heart failure. J Mol Cell Cardiol 39, 531-536, 2005.

Antunes F, Han D, Cadenas E. Relative contributions of heart mitochondria glutathione peroxidase and catalase to $\mathrm{H}(2) \mathrm{O}(2)$ detoxification in in vivo conditions. Free Radic Biol Med 33, 1260-1267, 2002.

Bai T, Wang F, Zheng Y, Liang Q, Wang Y, Kong J, Cai L. Myocardial redox status, mitophagy and cardioprotection: a potential way to amend diabetic heart? Clin Sci (Lond), 130, 1511-1521, 2016.

Bernatoniene J, Kopustinskiene DM, Jakstas V, Majiene V, Baniene R, Kursvietiene L, Masteikova R, Savickas A, Toleikis A, Trumbeckaite S. The effect of Leonurus cardiaca herb extract and some of its flavonoids on mitochondrial oxidative phosphorylation in the heart. Planta Med 80, 525-532, 2014.

Bowe JE, Franklin ZJ, Hauge-Evans AC, King AJ, Persaud SJ, Jones PM. Metabolic phenotyping guidelines: assessing glucose homeostasis in rodent models. J Endocrinol 222, G13-G25, 2014.

Brown DI, Griendling KK. Regulation of signal transduction by reactive oxygen species in the cardiovascular system. Circ Res 116, 531-549, 2015.

Cao H, Pauff JM, Hille R. X-ray crystal structure of a xanthine oxidase complex with the flavonoid inhibitor quercetin. J Nat Prod 77, 1693-1699, 2014

Cave A, Grieve D, Johar S, Zhang M, Shah AM. NADPH oxidase-derived reactive oxygen species in cardiac pathophysiology. Philos Trans R Soc Lond B Biol Sci 360, 2327-2334, 2005.

Conti G, Caccamo D, Siligato R, Gembillo G, Satta E, Pazzano D, Carucci N, Carella A, Del Campo G, Salvo A, Santoro D. Association of higher advanced oxidation protein products (AOPPs) levels in patients with diabetic and hypertensive nephropathy. Medicina (Kaunas) 55, 675, 2019.

Daubney J, Bonner PL, Hargreaves AJ, Dickenson JM. Cardioprotective and cardiotoxic effects of quercetin and two of its in vivo metabolites on differentiated h9c2 cardiomyocytes. Basic Clin Pharmacol Toxicol 116, 96-109, 2015.

Di Lisa F, Menabo R, Barbato R, Siliprandi N. Contrasting effects of propionate and propionyl-L-carnitine on energylinked processes in ischemic hearts. Am J Physiol 267, 455-461, 1994.

D’Oria R, Schipani R, Leonardini A, Natalicchio A, Perrini S, Cignarelli A, Laviola L, Giorgino F. The role of oxidative stress in cardiac disease: from physiological response to injury factor. Oxid Med Cell Longev 2020, 5732956, 2020.

Dudylina AL, Ivanova MV, Shumaev KB, Ruuge EK. Superoxide formation in cardiac mitochondria and effect of phenolic antioxidants. Cell Biochem Biophys 77, 99-107, 2019.

Eid HM, Haddad PS. The antidiabetic potential of quercetin: underlying mechanisms. Curr Med Chem 24, 355-364, 2017.

Gauer JS, Tumova S, Lippiat JD, Kerimi A, Williamson G. Differential patterns of inhibition of the sugar transporters GLUT2, GLUT5 and GLUT7 by flavonoids. Biochem Pharmacol 152, 11-20, 2018. 
Ghorbani A, Rashidi R, Shafiee-Nick R. Flavonoids for preserving pancreatic beta cell survival and function: a mechanistic review. Biomed Pharmacother 111, 947-957, 2019.

Gorbenko NI, Borikov OY, Ivanova OV, Taran KV, Litvinova TS, Kiprych TV, Shalamai AS. The effect of quercetin on oxidative stress markers and mitochondrial permeability transition in the heart of rats with type 2 diabetes. Ukr Biochem J 91, 46-54, 2019.

Gradinaru D, Borsa C, Ionescu C, Margina D. Advanced oxidative and glycoxidative protein damage markers in the elderly with type 2 diabetes. J Proteomics 92, 313-322, 2013.

Huynh K, Bernardo BC, McMullen JR, Ritchie RH. Diabetic cardiomyopathy: mechanisms and new treatment strategies targeting antioxidant signaling pathways. Pharmacol Ther 142, 375-415, 2014.

Huynh K, Kiriazis H, Du XJ, Love JE, Gray SP, Jandeleit-Dahm KA, McMullen JR, Ritchie RH. Targeting the upregulation of reactive oxygen species subsequent to hyperglycemia prevents type 1 diabetic cardiomyopathy in mice. Free Radic Biol Med 60, 307-317, 2013.

International Diabetes Federation. IDF Diabetes Atlas, 9th edn. Brussels, Belgium: 2019. Available at: https://www. diabetesatlas.org.

Jimenez R, Lopez-Sepulveda R, Romero M, Toral M, Cogolludo A, Perez-Vizcaino F, Duarte J. Quercetin and its metabolites inhibit the membrane NADPH oxidase activity in vascular smooth muscle cells from normotensive and spontaneously hypertensive rats. Food Funct 6, 409-414, 2015.

Kayama Y, Raaz U, Jagger A, Adam M, Schellinger IN, Sakamoto M, Suzuki H, Toyama K, Spin JM, Tsao PS. Diabetic cardiovascular disease induced by oxidative stress. Int J Mol Sci 16, 25234-25263, 2015.

Kicinska A, Jarmuszkiewicz W. Flavonoids and mitochondria: activation of cytoprotective pathways? Molecules 25, 3060, 2020.

Kumar S, Pandey AK. Chemistry and biological activities of flavonoids: an overview. ScientificWorldJournal 2013, 162750, 2013.

Lagoa R, Graziani I, Lopez-Sanchez C, Garcia-Martinez V, Gutierrez-Merino C. Complex I and cytochrome c are molecular targets of flavonoids that inhibit hydrogen peroxide production by mitochondria. Biochim Biophys Acta 1807, 1562-1572, 2011.

Lee MC, Velayutham M, Komatsu T, Hille R, Zweier JL. Measurement and characterization of superoxide generation from xanthine dehydrogenase: a redox-regulated pathway of radical generation in ischemic tissues. Biochemistry 53, 6615-6623, 2014.

Li JM, Gall NP, Grieve DJ, Chen M, Shah AM. Activation of NADPH oxidase during progression of cardiac hypertrophy to failure. Hypertension 40, 477-484, 2002

Lin S, Yang J, Wu G, Liu M, Luan X, Lv Q, Zhao H, Hu J. Preventive effect of taurine on experimental type II diabetic nephropathy. J Biomed Sci 17 (Suppl 1), S46, 2010.

Liu Q, Wang S, Cai L. Diabetic cardiomyopathy and its mechanisms: role of oxidative stress and damage. J Diabetes Invest 5, 623-634, 2014.

Lowry OH, Rosebrough NJ, Farr AL, Randall RJ. Protein measurement with the Folin phenol reagent. J Biol Chem 193, 265-275, 1951.

Lutz M, Fuentes E, Avila F, Alarcon M, Palomo I. Roles of phenolic compounds in the reduction of risk factors of cardiovascular diseases. Molecules 24, 366, 2019.

Miller GL. Protein determination for large number of samples. Anal Chem 31, 964, 1959.

Nguyen T, Nioi P, Pickett CB. The Nrf2-antioxidant response element signaling pathway and its activation by oxidative stress. J Biol Chem 284, 13291-13295, 2009.

Peoples JN, Saraf A, Ghazal N, Pham TT, Kwong JQ. Mitochondrial dysfunction and oxidative stress in heart disease. Exp Mol Med 51, 1-13, 2019.

Pereira DF, Cazarolli LH, Lavado C, Mengatto V, Figueiredo MS, Guedes A, Pizzolatti MG, Silva FR. Effects of flavonoids on a-glucosidase activity: potential targets for glucose homeostasis. Nutrition 27, 1161-1167, 2011.

Raza H, John A. Glutathione metabolism and oxidative stress in neonatal rat tissues from streptozotocin-induced diabetic mothers. Diabetes Metab Res Rev 20, 72-78, 2004.

Redondo A, Estrella N, Lorenzo AG, Cruzado M, Castro C. Quercetin and catechin synergistically inhibit angiotensin II-induced redox-dependent signalling pathways in vascular smooth muscle cells from hypertensive rats. Free Radic Res 46, 619-627, 2012.

Ritchie RH, Abel ED. Basic mechanisms of diabetic heart disease. Circ Res 126, 1501-1525, 2020.

Ritchie RH, Quinn JM, Cao AH, Drummond GR, Kaye DM, Favaloro JM, Proietto J, Delbridge LMD. The antioxidant tempol inhibits cardiac hypertrophy in the insulin-resistant GLUT4-deficient mouse in vivo. J Mol Cell Cardiol 42, 1119-1128, 2007. 
Sagor AT, Tabassum N, Potol A, Alam A. Xanthine oxidase inhibitor, allopurinol, prevented oxidative stress, fibrosis, and myocardial damage in isoproterenol induced aged rats. Oxid Med Cell Longev 2015, 478039, 2015.

Salehi B, Machin L, Monzote L, Sharifi-Rad J, Ezzat SM, Salem MA, Merghany RM, El Mahdy NM, Kılıç CS, Sytar O, Sharifi-Rad M, Sharopov F, Martins N, Martorell M, Cho WC. Therapeutic potential of quercetin: new insights and perspectives for human health. ACS Omega 5, 11849-11872, 2020.

Shah MS, Brownlee M. Molecular and cellular mechanisms of cardiovascular disorders in diabetes. Circ Res 118, 1808-1829, 2016.

Shi GJ, Li Y, Cao QH, Wu HX, Tang XY, Gao XH, Yu JQ, Chen Z, Yang Y. In vitro and in vivo evidence that quercetin protects against diabetes and its complications: a systematic review of the literature. Biomed Pharmacother 109, 1085-1099, 2019.

Skovso S. Modeling type 2 diabetes in rats using high fat diet and streptozotocin. J Diabetes Investig 5, 349-358, 2014.

Takahama U, Koga Y, Hirota S, Yamauchi R. Inhibition of xanthine oxidase activity by an oxathiolanone derivative of quercetin. Food Chem 126, 1808-1811, 2011.

Taylor EL, Armstrong KR, Perrett D, Hattersley AT, Winyard PG. Optimization of an advanced oxidation protein products assay: its application to studies of oxidative stress in diabetes mellitus. Oxid Med Cell Longev 2015, 496271, 2015.

Torres-Piedra M, Ortiz-Andrade R, Villalobos-Molina R, Singh N, Medina-Franco JL, Webster SP, Binnie M, Navarrete-Vazquez G, Estrada-Soto S. A comparative study of flavonoid analogues on streptozotocine-nicotinamide induced diabetic rats: quercetin as a potential antidiabetic agent acting via 11beta-hydroxysteroid dehydrogenase type 1 inhibition. Eur J Med Chem 45, 2606-2616, 2010.

Tsutsui H, Kinugawa S, Matsushima S. Oxidative stress and heart failure. Am J Physiol Heart Circ Physiol 301, H2181-2190, 2011.

Varga ZV, Giricz Z, Liaudet L, Hasko G, Ferdinandy P, Pacher P. Interplay of oxidative, nitrosative/nitrative stress, inflammation, cell death and autophagy in diabetic cardiomyopathy. Biochim Biophys Acta 1852, 232-242, 2015.

Wang Z, Chen K, Han Y, Zhu H, Zhou X, Tan T, Zeng J, Zhang J, Liu Y, Li Y, Yao Y, Yi J, He D, Zhou J, Ma J, Zeng C. Irisin protects heart against ischemia-reperfusion injury through a SOD2-dependent mitochondria mechanism. J Cardiovasc Pharmacol 72, 259-269, 2018.

Wein S, Behm N, Petersen RK, Kristiansen K, Wolffram S. Quercetin enhances adiponectin secretion by a PPARgamma independent mechanism. Eur J Pharm Sci 1, 16-22, 2010.

Zahedi M, Ghiasvand R, Feizi A, Asgari G, Darvish L. Does quercetin improve cardiovascular risk factors and inflammatory biomarkers in women with type 2 diabetes: a double-blind randomized controlled clinical trial. Int J Prev Med 4, 777-785, 2013.

Zhang H, Xiong Z, Wang J, Zhang S, Lei L, Yang L, Zhang Z. Glucagon-like peptide-1 protects cardiomyocytes from advanced oxidation protein product-induced apoptosis via the PI3K/Akt/Bad signaling pathway. Molec Med Rep 13, 1593-1601, 2016.

Zhang M, Kho AL, Anilkumar N, Chibber R, Pagano PJ, Shah AM, Cave AC. Glycated proteins stimulate reactive oxygen species production in cardiac myocytes: involvement of Nox2 (gp91phox)-containing NADPH oxidase. Circulation 113, 1235-1243, 2006. 